http://jmscr.igmpublication.org/home/ ISSN (e)-2347-176x ISSN (p) 2455-0450 crossref DOI: https://dx.doi.org/10.18535/jmscr/v9i8.05

\title{
Cavernous Sinus Thrombosis after Recovery from COVID-19 - A Rare Case Report
}

\author{
Authors \\ HN Sarker ${ }^{1}$, Masum Ahmed², Dr Muhammad Zubaer Hussain ${ }^{3}$ \\ ${ }^{1}$ Professor (Ex), Medicine, Sher E Bangla Medical College, Barishal, Bangladseh \\ ${ }^{2}$ Assistant professor, respiratory medicine, Sher E Bangla Medical College, Barishal, Bangladseh \\ ${ }^{3}$ Assistant professor, Medicine, Sher E Bangla Medical College, Barishal, Bangladseh \\ *Corresponding Author
}

HN Sarker

\begin{abstract}
A 40-year-old man presented with severe headache and pain and swelling of right eye for four days and consulted with an eye specialist who prescribed him analgesic and steroid, but he did not get any relief. The patient was hospitalized and treated at a medical college hospital for COVID-19 moderate illness, which was identified clinically and confirmed by RT-PCR positive and HRCT of the chest. He improved immensely without complications and was discharged from the hospital on 28/4/2021 following a 14-day hospital stay on rivaroxamine $10 \mathrm{mg}$ daily, vitamin $D$, vitamin $C$, and zinc. The cavernous sinus (CS) is a pair of cerebral dural venous sinuses found in the middle cranial fossa on each side of the sellaturcica. The cavernous sinus contains the third, fourth, and sixth cranial nerves, as well as the ophthalmic and maxillary divisions of the fifth cranial nerve and the internal carotid artery with its surrounding sympathetic plexus. CST related with COVID-19 is becoming more common, however therapy is problematic since the appropriate anticoagulant and length of therapy are unknown. We are now treating the patient with subcutaneous low molecular heparin.
\end{abstract}

\section{Introduction}

The world is facing the second wave of Coronavirus Disease 2019 (COVID-19) pandemic which is the most troublesome challenge to public health. COVID- 19 caused by severe acute respiratory syndrome coronavirus-2 (SARS CoV2) started in Hubei Province, People's Republic of China in December 2019 $9^{[1]}$. The virus has since spread globally rapidly and World Health Organization (WHO) declared COVID- 19 pandemic on 11th March 2020. The second wave is running and nobody knows where we are in the course of this disease. It becomes a significant challenge for the public health, science, and medical sectors ${ }^{[2]}$.

COVID-19 is primarily the disease of respiratory tract and initially the mortalityis related to severe acute respiratory distress syndrome (ARDS), but more and more understanding of this disease in course of time, it revealed that COVID-19caused an inflammatory response with severe systemic complications like stroke, acute liver failure and acute renal failure ${ }^{[3]}$.

Neurologic complications are frequent in patients with COVID-19, occurring in $36 \%$ to $65 \%$ of hospitalized patients ${ }^{[4,5]}$. Stroke is the most 
common neurological complication in COVID-19 patients accounting 5\% in critically ill patients and more in other COVID-19 patients ${ }^{[6]}$.

COVID-19 is known to increase the risk of developing venous thromboembolism; the incidence of cerebral venous sinus thrombosis/cavernous sinus thrombosis is being increasingly reported. Venous thromboembolism has become an important cause of morbidity and mortality in patients with COVID-19, in the intensive care unit (ICU) and in the general inpatient setting, even after receiving prophylactic/therapeutic anticoagulation ${ }^{[7]}$.

We report the case of an adult patient who presented a cavernous sinus thrombosis after recovery from COVID-19.

\section{Case Report}

A 40-year-old man presented with severe headache and pain and swelling of right eye for four days and consulted with an eye specialist who prescribed him analgesic and steroid, but he did not get any relief. In the meantime he developed fever for one day and came to my chamber on 01/5/21.Physical examination showed proptosis of right eye, chemosis (Fig.1) and external ophthalmoplegia with limitation of ocular movements in all directions of gaze. Patient is conscious, oriented and his temperature is $38{ }^{\circ} \mathrm{C}$ and blood pressure 130/85 $\mathrm{mm} \mathrm{Hg}$.

The patient suffered from COVID-19 moderate disease diagnosed by clinical symptoms and confirmed by RT-PCR positive and HRCT of chest (Fig.2), and was admitted and treated in a medical college hospital. He recovered fully without any complication and discharged from hospital on 28/4/2021 after 14 days of hospital stay with rivaroxamine $10 \mathrm{mg}$ daily, vit-D, vit-C and Zinc.

After 2 days of hospital discharge, he developed headache and pain in right eye which increased gradually to its peak with one day. Right eye became swollen and protruded forward.

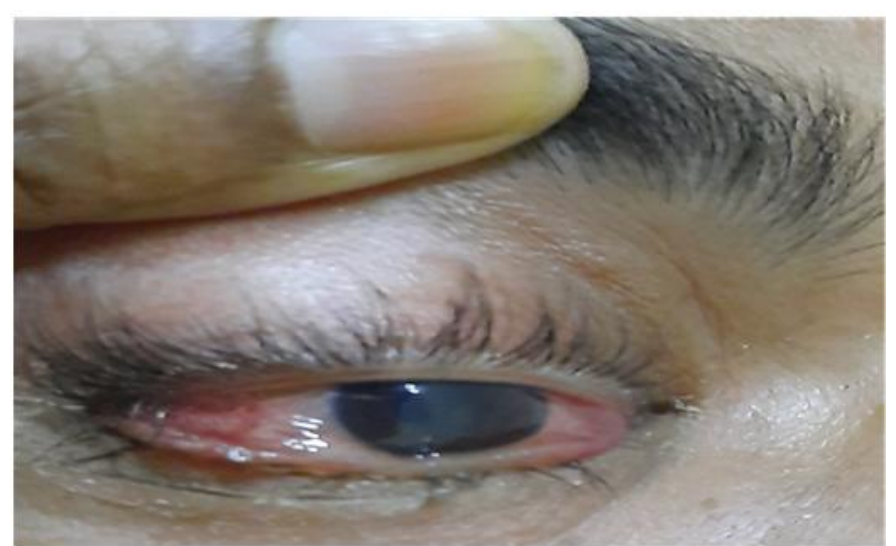

Fig.1 Chemosis and proptosis

With this complaint he visited an eye specialist who referred the patient to me. He is diagnosed as cavernous sinus thrombosis supported by MRI with contrast (Fig.3) and admitted into Hospital. $\mathrm{He}$ is being treated with low molecular weight heparin injection, inj. Ceftriaxone and supportive measures. His condition is improving observed at the time of writing this case report.

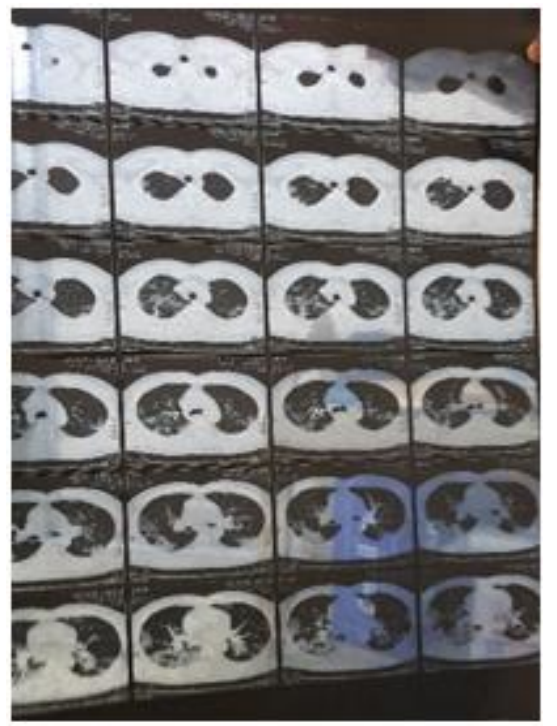

Fig. 2 HRCT of chest showing typical ground glass appearance 


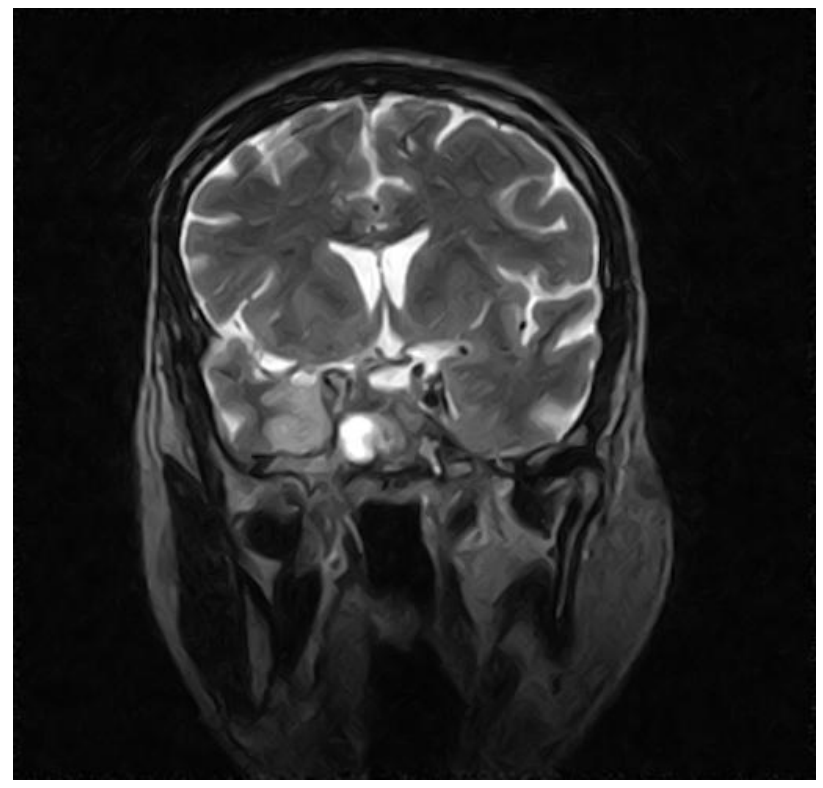

Fig. 3 MRI (T2) showing cavernous sinus thrombosis

\section{Discussion}

The cavernous sinus (CS) is a pair of cerebralduralvenous sinuses located on each side of the sellaturcica in the middle cranial fossa. The third, fourth, and sixth cranial nerves, ophthalmic and maxillary divisions of the fifth cranial nerve, and internal carotid artery with its surrounding sympathetic plexus run within the cavernous sinus. The CS drains blood from the face through the facial veins via pterygoid plexus and from the orbit through ophthalmic veins and into the internal jugular veins via both the superior and inferior petrosal sinuses. Blood can flow in either direction, as the CS are valveless veins.

Cavernous sinus thrombosis (CST) was first described by Bright in 1831 as a complication of epidural and subdural contamination ${ }^{[8]}$. CST usually occurs due to spread of infection from its draining areas such as mid-face, paranasal sinuses, teeth, orbit, and oral cavity i.e. septic thrombosis $^{[9]}$. Although its incidence is low, the mortality rate from CST was almost $100 \%$ prior to antibiotics era. Recently with the COVID19infection there is increasing reports with cerebral venous thrombosis as a complication of the disease; so we present a case of CST soon after recovery from COVID-19.
Hypercoagulability has been shown to be a manifestation of severe COVID-19 pneumonia ${ }^{[10}$, ${ }^{11]}$.Pathogenesis is the generation and inhibition of fibrinolysis ${ }^{[12]}$. Furthermore, hypoxemia is associated with an elevation of blood viscosity and activation of hypoxia-related genes that mediate coagulation and fibrinolysis, favoring thrombotic events ${ }^{[13]}$.

The superior sagittal sinus thrombosis is the most frequently reported cerebral venous thrombosis and septic thrombosis is the most common cause of CST. Therefore our case provides a diagnostic challenge in the absence of features of infection.

CST associated with COVID-19 is increasingly reported but its treatment is difficult because the optimal choice of anticoagulant and duration of treatment is not known ${ }^{[14]}$. We use subcutaneous low molecular heparin and patient is now under treatment.

\section{Conclusion}

This case provides support for the postulation that COVID-19 is a serious contributor to hypercoagulation, increasing the motality of the disease. Hence, a guideline should be developed regarding the thromboprophylaxis and treatment of treatable complications like this.

\section{Acknowledgements}

Gratitude and thanks to all frontline fighters against COVID-19 pandemic.

\section{Compliance with Ethical Standards Conflict of interest}

As a corresponding author and on behalf of coauthors, I declared that I take full responsibility for the integrity of the content of the manuscript. There is no conflict of interest needed to be declared. There is no financial support received from any organization.

Consent was taken from family member.

\section{References}

1. WHO/ Pneumonia of unknown cause China. 2020 [cited 2021 Apr 24]; Available from: 
https://www.who.int/csr/don/05-january-

2020-pneumonia-of-unkown-cause-

china/en/ de

2. Wit E, van Doremalen N, Falzarano D, Munster VJ. SARS and MERS: recent insights into emerging coronaviruses. Nat Rev Microbiol. 2016;14(8):523-34.

3. Aghagoli G, Gallo Marin B ,Soliman LB, Sellke FW. Cardiac involvement in COVID-19 patients: risk factors, predictors, and complications: a review. J Card Surg 2020;35(6):1302-5 .

4. Mao L, Jin H, Wang M, Hu Y, Chen S, He $\mathrm{Q}$, et al. Neurologicmanifestations of hospitalized patients with coronavirus disease 2019 in Wuhan, China. JAMA Neurol 2020.

5. Fan S, XiaoM, Han F, Xia P, Bai X, Chen $\mathrm{H}$, et al. Neurological manifestations in Critically Ill patients with COVID-19:a retrospective study. Front Neurol 2020; 11:806.

6. Carneiro T DJ, Leung LY, Nobleza COS, Marulanda-Londono E, Hathidara M, et al. Intravenous tPA for acuteischemic stroke in patients with COVID-19. J Stroke Cerebrovasc Dis 2020;2020(105201).

7. Lodigiani $C$, Iapichino $G$, Ferrazzi $P$, Sebastian T ,Kucher $\mathrm{N}$,Studt J-D ,et al. Venous and arterial thromboembolic complications in COVID-19 patients admitted to an academic hospital in Milan, Italy. Thromb Res 2020;191:9-14 .

8. Tempea V, Gorun G (1959) Cavernous sinus thrombosis. AMAArch Otolaryngol 69:220-223

9. Pavlovich P, Looi A, Rootman J (2006) Septic thrombosis of thecavernous sinus: two different mechanisms. Orbit 25:39-43

10. Iba T, Levy JH, Levi M, Connors JM, Thachil J. Coagulopathy of coronavirus disease 2019. Crit Care Med 2020; 48:1358-64.
11. Connors JM, Levy JH. COVID-19 and its implications for thrombosis and anticoagulation. Blood 2020;135:2033-40.

12. Uthman IW, Gharavi AE (2002) Viral infections and antiphospholipid antibodies. Semin Arthritis Rheum 31:256-63 (CrossRef Medline)

13. Gupta N, Zhao YY, Evans CE (2019) The stimulation of thrombosis by hypoxia. Thromb Res 181:77-83 (Cross-Ref Medline)

14. Costa A, Weinstein ES, Sahoo DR, Thompson SC, Faccincani R, Ragazzoni L. How to build the plane while flying: VTE/PE thromboprophylaxis clinical guidelines for COVID-19 patients. Disaster Med Public Health Prep 2020;55:1-15. 